\title{
PRODUCTION AND MEASUREMENT OF HIGH VACUA.
}

By J. E. Shrader and R. G. Sherwood.

$\mathrm{D}^{\mathrm{u}}$ URING the last few years the importance of very high vacua has been increasingly recognized. Especially is this true in the case of thermionic emission from hot bodies, the photo-electric effect and in other allied phenomena. In order to be able to produce and measure vacua of the highest order, the authors began the investigation of various pumps and gauges and treatment of glass vessels that the best results might be obtained.

The diffusion pump devised by Gaede ${ }^{1}$ and improved by Langmuir ${ }^{2}$ practically displaces all other means of obtaining a high vacuum. Previous to the appearance of this pump Gaede's molecular pump was probably the best means at our disposal for producing a high vacuum. In spite of the serious objection of any pump constructed of metal which continually evolves gas during its operation, Gaede records a pressure of $2 \times 10^{-7} \mathrm{~mm}$. Hg. obtained by this pump. Very high vacua can be obtained by making use of the extraordinary absorptive power for gases by cocoanut charcoal when immersed in liquid air. Oxygen, nitrogen, water vapor, etc., are strongly absorbed, hydrogen somewhat less and helium and neon least of all. It is necessary that the charcoal should be heated to 500 or $600^{\circ} \mathrm{C}$. and the emitted gases pumped off to a very good vacuum before the liquid air is applied. Angerer ${ }^{3}$ by this method has obtained a pressure of $8 \times \mathrm{IO}^{-7} \mathrm{~mm}$. $\mathrm{Hg}$.

When pressures of the order mentioned above are to be measured the McLeod gauge is no longer serviceable. A gauge of this type to measure pressure even as low as $\mathrm{I} \times 10^{-5} \mathrm{~mm} . \mathrm{Hg}$ has to be of inconvenient size and also at this pressure gases given off by the gauge, since it is difficult to give it heat treatment, are of considerable importance. The wire type of gauge devised by Pirani ${ }^{4}$ and improved by $\mathrm{Hale}^{5}$ can be given heat treatment, but have not as yet been able to record changes in pressure lower than $2 \times \mathrm{IO}^{-5} \mathrm{~mm}$. $\mathrm{Hg}$. The molecular gauge by Dushman ${ }^{6}$

1 Gaede, Ann. d. Phys., 46, 357, I9I5.

${ }^{2}$ Langmuir, Phys. Rev., 8, 48, I9I6.

${ }^{3}$ Angerer, Ann. d. Phys., I9II.

${ }^{4}$ Pirani, Verh. d. Deutsch. Phys. Gesell., 24, p. 686, 1906.

${ }^{5}$ Hale, Trans. Am. Electrochem. Soc., 20, 243, I9I r.

${ }^{6}$ Dushman, Phys. Rev., Vol. V., 212, I915. 
theoretically is able to measure lower pressures, but the difficulty in operating the mechanism and the fact that it is made of comparatively large masses of metal which evolve gases, does not make this type of gauge appear promising. Knudsen devised a type of gauge which later improved by him seems to meet all the requirements of a sensitive and accurate gauge which is independent of the kinds of gases or vapors present. Quite recently Buckley ${ }^{1}$ has devised an ionization gauge in which the residual gas is ionized by electrons given off by an incandescent filament accelerated by a potential of about 200 volts. The ionization so produced is measured by means of a third electrode in connection with a sensitive galvanometer. The ratio of the ionic current to the thermionic current is equal for any given gas to a constant times the pressure. From some work done by one of the authors this gauge did not prove very satisfactory, either from constancy of reading or of sensibility at very low pressures. Furthermore the gauge is not independent of the nature of gases or vapors present and has to be calibrated for known gases. It is quite obvious that the audion or pliotron can be used in the same way as an ionization gauge.

In this paper the diffusion pump and the Knudsen molecular gauge have been the means selected for the production and measurement of high vacua. In investigating the operation of these instruments attempts have been made to improve both by certain modifications.

\section{The Mercury Diffusion Pumf.}

Langmuir's modification of Gaede's diffusion pump consists in providing a much wider opening for diffusion so that greater speed is secured. In his first pump the condensed mercury in returning came into contact with the hot tube carrying the mercury blast so that some mercury reëvaporated and operated against the intake side of the pump. In his later pump the mercury blast is carried forward and enters the condensing chamber from above and the condensed mercury reënters the boiler by a side tube, thus avoiding the former difficulty.

A New Design of Diffusion Pump.-To maintain the upright form of the pump which is of advantage in glass blowing and yet have all the advantages of this latter type of pump a new pump was designed which is simple in construction. Fig. I is a diagram of this pump. The tube $B$, carrying the blast of mercury vapor from the reservoir $A$, extends through the high vacuum chamber $C$ into the condensing chamber $D$. A sleeve $E$ separates the lower part of the condensing chamber from the tube $B$, forming a sort of catch-basin for the mercury condensed in $D$.

1 Buckley, Nat. Acad. Sci. Proc., 2, p. 683, I9I6. 
This mercury is returned to the reservoir by the tube $F$ without passing through the high vacuum chamber $C$. This entirely obviates the objec-

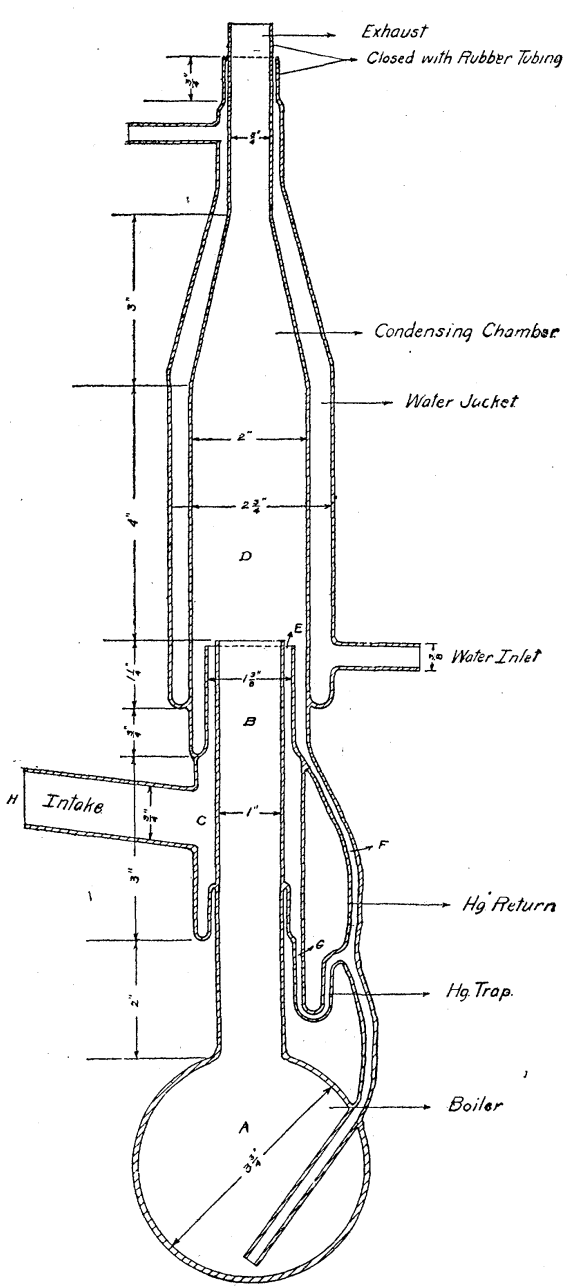

Fig. 1.

Mercury Diffusion Pump. tionable feature of mercury coming into contact with the hot tube $B$. The tube $G$ returns to the reservoir any mercury that might by chance get into $C$. No mercury has ever been observed in $C$ during normal operation of the pump. The return tube $G$, as well as the annular trough at the bottom of $C$, was inserted by way of precaution. The upper part of the condensing chamber is made cone-shaped so that mercury condensed at this point will slide along the wall and not fall through the opening between $B$ and $E$ into the chamber $C$. The water jacket is sealed to the condenser at the bottom about one inch below the end of the tube $E$ and is made water tight by a rubber tube connection at the top. Some of the dimensions of a standard size pump were as follows: The reservoir $A$ was $3 \frac{3}{4}$ inches in diameter. Tubes $B$ and $E$ were $I$ inch and $\mathrm{I} 3 / 8$ inches in diameter respectively. The condensing chamber $D$ was 2 inches in diameter and 7 inches long. The water jacket was $2 \frac{1}{2}$ inches in diameter.

Sleeve $D$ ends about $\mathrm{I} / 32$ of an inch below $E$ so that the chance of mercury vapor striking it and being deflected into $C$ is small. The intake tube $H$ was $3 / 4$ inch in diameter.

\section{The Knudsen Absolute Gauge.}

An absolute gauze, independent of the nature of gases or vapors, was devised by Knudsen ${ }^{1}$ in I9IO suitable for measuring pressures as

1 Knudsen, Ann. d. Phys., IV., 32, 809, I9Io. 
low as $10^{-5} \mathrm{~mm}$. of $\mathrm{Hg}$. In $1914^{1}$ he made a much more sensitive gauge of this type capable of indicating pressures as low as $1.5 \times 10^{-7} \mathrm{~mm}$. $\mathrm{Hg}$. A modified form of this gauge was made by Woodrow ${ }^{2}$ which was sensitive to a pressure as low as $3 \times 10^{-8} \mathrm{~mm}$. $\mathrm{Hg}$. though he does not record any pressures actually obtained lower than $\mathrm{I} \times \mathrm{IO}^{-6} \mathrm{~mm}$. of $\mathrm{Hg}$.

Theory of the Gauge.-This gauge has the advantage of great sensibility and independence of the nature of the gas. It operates on the principle of molecular bombardment of a movable vane from an electrically heated platinum strip. The pressure of the gas is calculated from the physical dimensions of the movable vane, the difference of temperature between the heated strip and the vane, the torsion of the suspension and the angular deflection of the vane, which are all readily determined.

Assuming that the pressure is so small that the mean free path is large in comparison to the distance between the heating strip and the vane, from theoretical considerations, Knudsen has developed the formula

$$
p=\frac{2 K}{\sqrt{\frac{T}{T_{2}}}-\mathrm{I}} \text { dynes/cm. }{ }^{2}
$$

where $p=$ pressure of the gas in dynes per square centimeter.

$K=$ a constant of the gauge.

$T_{1}=$ the absolute temperature of the heated strip.

$T_{2}=$ the absolute temperature of the movable vane.

For small differences of temperature this becomes approximately

$$
p=4 K \frac{T_{2}}{T_{1}-T_{2}} \text { dynes } / \mathrm{cm} .{ }^{2} .
$$

If the physical dimensions of the gauge are inserted this formula becomes

where

$$
p=\frac{4 \pi^{2} I D}{r A t^{2} d} \frac{T_{2} \cdot}{T_{1}-T_{2}} \text { dynes } / \mathrm{cm} . .^{2},
$$

$$
\begin{aligned}
I & =\text { moment of inertia of the moving vane. } \\
r & =\text { mean radius of the moving vane. } \\
A & =\text { area of one moving vane. } \\
t & =\text { period of vibration of the vane. } \\
D & =\text { scale deflection. } \\
d & =\text { scale distance. } \\
T_{1} & =\text { absolute temperature of the heated strip. } \\
T_{2} & =\text { absolute temperature of the movable vane. }
\end{aligned}
$$

${ }^{1}$ Ann. d. Phys., 44, 525, I914.

${ }^{2}$ Woodrow, Phys. Rev., 4, 49I, I9I4. 
If we express $T_{1}-T_{2}$ in terms of the resistance of the heating strip at temperatures of $\mathrm{o}^{\circ} \mathrm{C}$., $T_{1}$ and $T_{2}$ thus become

$$
T_{1}-T_{2}=\frac{R_{1}-R_{2}}{R_{0}{ }^{a}}
$$

where $a$ is the temperature coefficient of the platinum strip. The formula for the pressure then becomes

$$
p=\frac{4 \pi^{2} I D}{r A t^{2} d} \frac{a R_{0}}{R_{1}-R_{2}} T_{2} \text { dynes } / \mathrm{cm} .^{2}
$$

Knudsen has shown experimentally that this approximate formula holds with very small error up to differences of temperature of $250^{\circ} \mathrm{C}$. $\mathrm{He}$ has also checked the formula from .oor $\mathrm{mm}$. to oooor $\mathrm{mm}$. $\mathrm{Hg}$. and finds that it holds extremely well. At higher pressures than .oor $\mathrm{mm}$. the mean free path of the molecule is no longer large compared with the

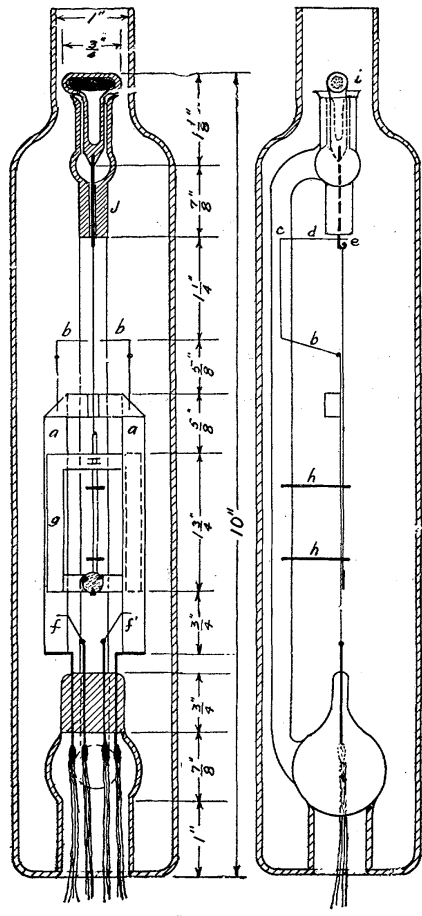

Fig. 2.

Knudsen Absolute Gauge. distance between the vane and the heating strip, hence some of the energy of the molecules is lost in collisions and the above formula no longer holds.

Description of the Gauge.-A gauge possessing important improvements, we believe, over those already referred to, viz.: (I) the method of supporting the platinum heating strip, (2) the kind of suspension used and (3) the manner of suspending and controlling the movable vane, should justify a description of a further modified form of the Knudsen gauge.

The gauge is shown in Fig. 2. It is inclosed in a hard glass tube 2 inches in diameter and 9 inches long. The heating strip $a a$ is of platinum .oI $8 \mathrm{~mm}$. thick and $7.5 \mathrm{~mm}$. wide with a total length of $18 \mathrm{~cm}$. It is folded at the top forming a cross piece and two parallel sides. The ends are brazed to 20 mil tungsten leading-in wires at the bottom. Fifteen mil tungsten wires $b$ sealed into the glass-rod support serve as a spring support for the platinum strip. This allows accurate adjustment of the strip and sufficient tension is secured to keep the strip taut during heating. One of these wires is carried up the glass-rod support, sealed 
into it at $c$, leaving a free end $d$ to serve for electrical connection of the moving vane to the heating strip. Connection is made by the wire pressing under tension against the tungsten wire $e$ to which the suspension of the vane is fastened. Potential leads of fine platinum wires $f f$ are welded to the strip about one centimeter from the ends and are brazed to tungsten sealing-in wires.

The movable rectangular vane $g$ is made of aluminum $.0076 \mathrm{~cm}$. thick. A standard size adopted is $3.2 \mathrm{~cm}$. by $4 \mathrm{~cm}$. outside dimensions, the width of the vane being $.5 \mathrm{~cm}$. Because of liability of warping during heat treatment the vane is stiffened by an aluminum wire passing through slits at the top and a hole at the bottom into which the wire is hooked and fastened firmly. For portability, two copper wires $h$ are sealed into the glass-rod support while the free end formed loops around the rod, these forming guides for the vane. The mirror is fastened at the bottom of the vane by leaving a small projection of the aluminum at the lower edge and cutting out small tongues from the material of the vane on either side. The mirror is laid in place and the projection and the two tongues are pressed closely over it, holding it securely.

Silver mirrors were tried, but failed to withstand the heat treatment to which the gauge and system were subjected. Mirrors made by coating microscope cover glass with china decorator's platinum solution, followed by baking at $500^{\circ}$ solved this difficulty.

The distance between the heating strip and the vane is adjusted from outside the case by magnetic control on a piece of soft iron $i$ sealed into a glass stem to which the suspension is fastened.

The suspension is .0005-inch tungsten wire. This is fastened to small aluminum hooks around which the wire is wrapped several times after which the hooks are pressed firmly together. This method is not difficult and holds the wire securely. A hook on the end of a tungsten wire sealed into a glass stem, the free end passing through a capillary rod $j$ on the glass support serves to hold the suspension.

The use of phosphor-bronze or silver as suspensions proved unsatisfactory as they were readily attacked by mercury vapor.

A gauge such as has been described, using a .0005-inch tungsten suspension from 6 to $7 \mathrm{~cm}$. long, has such a sensibility that a scale deflection of $\mathrm{I} \mathrm{mm}$. at a meter's distance with a temperature difference of $150^{\circ} \mathrm{C}$. between the heating strip and the movable vane indicates pressures of $\mathrm{I} \times \mathrm{IO}^{-8}$ to $5 \times \mathrm{IO}^{-8} \mathrm{~mm}$. Hg. One gauge of other dimensions than those given above would indicate a pressure of $5 \times \mathrm{IO}^{-9} \mathrm{~mm}$. $\mathrm{Hg}$. under the same conditions.

Operation of the Gauge.-The gauge was sealed to the system and ad- 
justed so that the vane hung parallel to the heating strip. The distance between the movable vane and the strip is adjusted by the magnetic control to about one millimeter or less. Since damping at low pressures is quite inappreciable this is accomplished by a laminated electro-magnet. An electro-magnet is quite necessary since all samples of aluminum of which the vanes were made contain sufficiently large amounts of magnetic impurities to produce appreciable magnetic effects. The gauge was screened from electrostatic disturbances and from direct light by a screen of thin aluminum on the outside of the case. A small hole in front of the mirror allowed the use of a lamp and scale for the reading of the deflections. Careful observations showed that no difficulties arose from the light entering the gauge from the lamp.

The difference in resistance which appears in the formula for calculating the pressure was determined by a Leeds and Northrup potentiometer

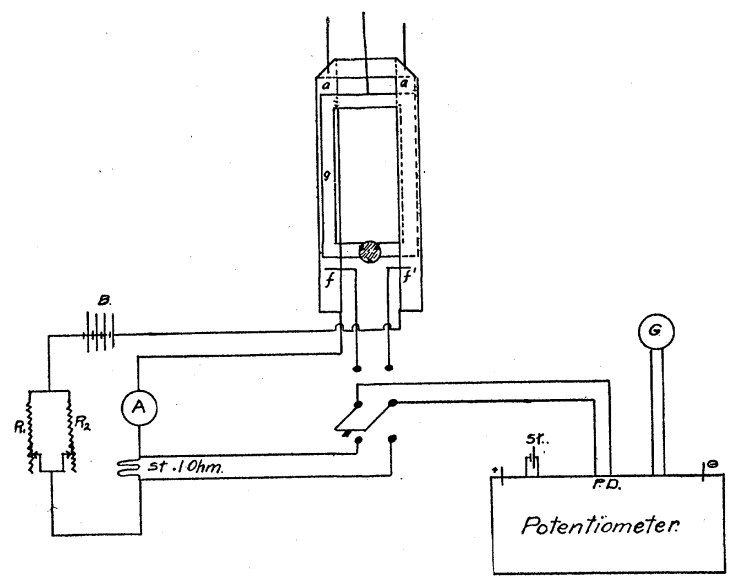

Fig. 3.

together with a .I ohm Standard shunt. Fig. 3 is a diagram of the electrical connections. $P$ is the potentiometer with the driving battery $B a$, a galvanometer $G$ and a Weston Standard cell $C$. In the gauge circuit is a battery of 6 volts, a high resistance $R_{2}$ ( $\mathrm{I}$, ooo ohms) and a low resistance $R_{1}$ (8o ohms) and the standard .I ohm shunt $S$. A double-pole double-throw switch makes connections so that the fall in potential across the heating strip from $f$ to $f^{\prime}$ or across the standard shunt can be determined. From these observations the value of the current through the strip and consequently the resistance of the strip can be determined.

The resistance at room temperature was always determined by the same method using such a small current by inserting $R_{2}$ that no appreciable heating of the strip took place. 
The temperature coefficient was determined in the same manner, the gauge, before sealing in the case, being immersed in an oil-bath and its resistance determined at different temperatures. The temperature coefficient for different specimens of platinum varied widely ranging from .oo3o down as low as .oor3.

The absolute gauge was checked against a McLeod gauge of 750 c.c. capacity. Since the gauge which has been described is quite sensitive only a very small difference of temperature between the strip and the vane can be used in comparing it with the McLeod gauge in the region of $\mathrm{I} \times \mathrm{IO}^{-5} \mathrm{~mm}$. of $\mathrm{Hg}$ which is the lower limit of this gauge. Though considerable uncertainty attends the measurement of a small difference of temperature in a glass vessel, subject to fluctuations of temperature in the room, the agreement with the McLeod gauge in the region of $3 \times \mathrm{IO}^{-5} \mathrm{~mm}$. $\mathrm{Hg}$ was about Io per cent. This held both for readings with and without liquid air on the trap, correction being made for the vapor pressure of mercury in the latter case.

With a gauge of such sensibility it might be thought that radiation pressure from the heated strip might be noticeable at the higher temperatures. Calculations were accordingly made from the best available data which showed that such pressure was too small to be detected. This was also checked experimentally. During the exhaustion of a bulb a pressure lower than could be detected by the gauge was obtained. A pressure of $2 \times 10^{-8} \mathrm{~mm}$. $\mathrm{Hg}$ would give a deflection of $\mathrm{I} \mathrm{mm}$. with a temperature difference of $150^{\circ}$ between the strip and vane. No deflection was observed. The temperature difference was further increased to $250^{\circ}$ without any noticeable deflection. This shows conclusively that radiation pressure from the heated platinum strip does not affect a gauge of this sensibility though the temperature of the platinum strip is raised to $525^{\circ}$ absolute.

The gauge thus described has been very satisfactory for the measurement of high vacua. Though we have no means of checking the instrument at extremely low pressures we have, from theoretical considerations, no doubt of its accuracy. With the diffusion pump several glass vessels have been exhausted to a vacuum indicated by the gauge as being from $2 \times 10^{-8}$ to $5 \times 10^{-8} \mathrm{~mm}$. Hg. Gauges still more sensitive could be constructed if need should arise. Others less sensitive, capable of being checked with a McLeod gauge to a pressure of $\mathrm{I} \times \mathrm{IO}^{-3} \mathrm{~mm} . \mathrm{Hg}$. have been constructed. These could measure a pressure as high as $\mathrm{I} \times \mathrm{IO}^{-2}$ if the gauge is calibrated by comparison with a McLeod gauge since the calculated pressure does not hold over this higher range.

Operation of the Diffusion Pump.-The pump system consisted of the 
house vacuum-3 to $5 \mathrm{~mm}$. $\mathrm{Hg}$ - serving as backing for a Trimount oil pump which gave a pressure as low as $3 \times \mathrm{IO}^{-4} \mathrm{~mm}$. Hg. This Trimount pump was used as a backing pump for the diffusion pump. The pump system was as short as possible and consisted of a liquid-air trap, a Knudsen absolute gauge and a cylindrical bulb of about I,500 c.c. capacity. The connecting tube was three fourths inch in diameter. To reduce the speed and to be able later to seal off the bulb and gauge, a constriction was made in the connecting tube.

Without heat treatment, pressures lower than $\mathrm{I} \times \mathrm{IO}^{-5}$ could not be obtained. With air introduced into a system which had been previously exhausted at a temperature of about $500^{\circ} \mathrm{C}$., the change in pressure during the operation of the pump followed closely the equation

$$
p_{2}=p_{1} e^{-K t}
$$

where $p_{2}$ is the pressure at any given time $t, p_{1}$ is the pressure when $t=0$, and $K$ is a constant of the pump.

From this equation, Gaede has given a definition of the speed of exhaustion,

$$
S=\frac{V}{t} \log \left(\frac{p_{1}}{p_{2}}\right), \text { replacing } K \text { by } \frac{S}{V},
$$

where $S$ is the speed of the exhaustion and $V$ is the volume.

At extremely low pressures the equation above does not hold since even in a thoroughly heat-treated system the gases and vapors coming from the walls of the glass become appreciable.

Lowest Pressure Obtained as Measured by the Gauge.-Preliminary work showed that treatment at high temperature of all glass in the system is absolutely essential when a high vacuum is desired. With the Trimount pump running, the gauge, bulb, liquid-air trap and connecting tubing were heated to $500^{\circ} \mathrm{C}$. for two hours. Then the liquidair trap was allowed to cool and liquid air was applied. The diffusion pump was then started and the heating of the bulb and gauge was continued for one hour longer. After cooling, the gauge was adjusted and observations showed the pressure to be $2 \times 10^{-7} \mathrm{~mm}$. Hg. After pumping overnight the vacuum showed no material improvement. Heat was again applied to the bulb and gauge for an hour while the connecting tubing was again heated. Observations now showed that the pressure was too low to be measured with the gauge which would give a deflection of $\mathrm{I} \mathrm{mm}$. for a pressure of $2 \times 10^{-8} \mathrm{~mm}$. Hg. In subsequent exhaustions of bulbs of the same kind, pressures of from $8 \times \mathrm{IO}^{-8}$ to $2 \times 1 \mathrm{IO}^{-8} \mathrm{~mm}$. $\mathrm{Hg}$ were observed. 
Tésts of the Diffusion Pumf in Connection with the Gauge.

Variation of Speed of Exhaustion with Watts Input.-With the speed of exhaustion purposely cut down by the constriction before mentioned,

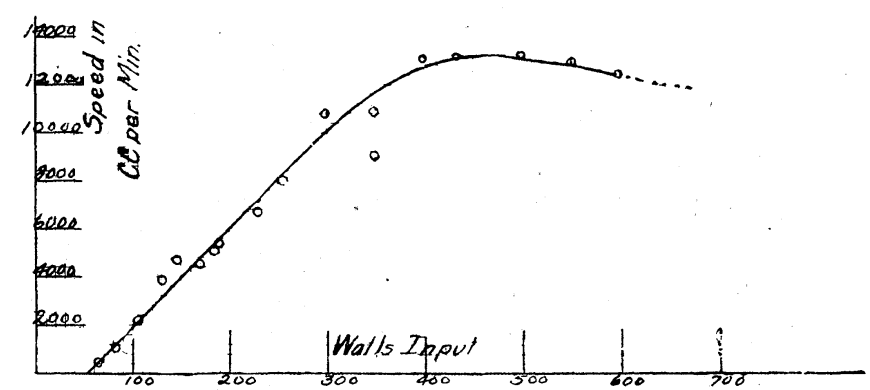

Fig. 4.

the backing pressure, $3 \times \mathrm{IO}^{-4} \mathrm{~mm}$. $\mathrm{Hg}$, was kept constant and measurements of the speed of exhaustion were made with varying watts input in the heater. From the curve, Fig. 4, it is seen that the smallest input is about 65 watts. The speed under these conditions was comparatively slow. There is a gradual increase of speed with wattage up to 300 watts after which the increase was much less up to 350 watts. From 350 to 600 watts the speed was practically constant though showing a slight decrease with increasing wattage.

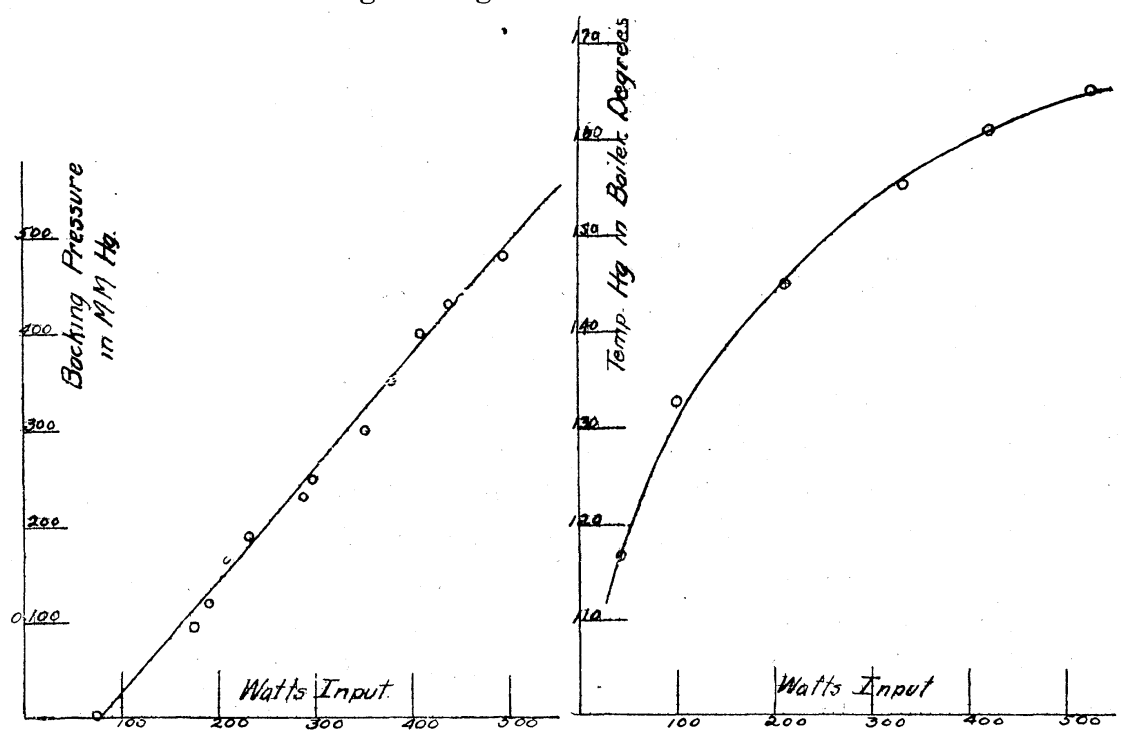

Fig. 5.

Fig. 6.

Variation of Critical Backing Pressure with Wattage.--The pump was 
operated until a pressure of $3 \times 10^{-7} \mathrm{~mm}$. $\mathrm{Hg}$ was recorded after which the deflection of the gauge was practically constant. Then backing pressure for different wattages were adjusted until the pressure indicated by the gauge just began to increase. The pressure corresponding to this condition is called the critical pressure for this particular wattage. It is seen from the curve, Fig. 5, that the critical backing pressure is proportional to the watts input over the range of backing pressures $3 \times \mathrm{Io}^{-4} \mathrm{~mm} . \mathrm{Hg}$ to $.6 \mathrm{~mm}$. $\mathrm{Hg}$.

Relation between Critical Backing Pressure and Vapor Pressure.-A glass tube was sealed into the side of the mercury reservoir extending below the surface of the mercury. A small portion of mercury was put into the tube and a thermometer was inserted. Thus the variation of the temperature of the mercury with watts input of the heater was observed. The curve is shown in Fig. 6. From comparison with vapor pressure-temperature curves for mercury it follows that critical backing pressure is a linear function of the vapor pressure of mercury.

Variation of Speed with Watts Input at Different Backing Pressures.At low backing pressures the speed of exhaustion at wattages above the wattage corresponding to the critical backing pressure gradually increased with the wattage and reaches a maximum after which there is a slight

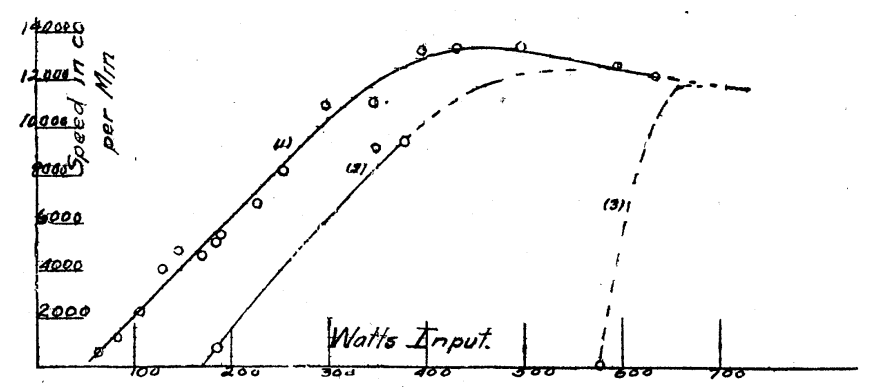

Fig. 7.

decrease in speed, as is shown by curve $I$, Fig. 7 . With a constant backing pressure of $.06 \mathrm{~mm}$. the change in speed with watts input becomes greater and reaches a maximum slightly lower, but coincides with curve $I$ at the higher wattages (see curve 2, Fig. 7). At .6 mm. backing pressure a small increase in wattage above the wattage corresponding to the critical backing pressure causes the speed to assume almost immediately its maximum value still lower than for curves $I$ and 2 , but coincides with them for higher wattages. (See curve 3, Fig. 7.)

WESTINGHOUSE RESEARCH LABORATORY, October I, r9I7. 